\title{
Research on structural dynamic characteristics of continuous steel box girder-bridge with lager ratio of wide-span
}

\author{
Haijun Yin ${ }^{1,2}$, Ziqing $\mathrm{Li}^{1}$, Xianwu $\mathrm{Hao}^{1}$ \\ ${ }^{1}$ School of highway Engineering, Chang ${ }^{6}$ an University, $\mathrm{Xi}^{\circ}$ an 710064 , China \\ ${ }^{2} \mathrm{Xi}^{\prime}$ an Architecture \& Technology University, $\mathrm{Xi}^{\prime}$ an 710055,China;
}

\begin{abstract}
Structure natural frequency and mode of vibration can not only reflect the structure modal parameters of dynamic properties, but also incarnate the dynamic evaluation characteristics of bridge structure. This paper applies ANSYS to establish the finite element model based on a continuous steel box girder bridge in order to obtain the corresponding modal analysis parameters. Through the environmental stimulation test, The results show that height of the steel box girder and the setting of diaphragm plate is reasonable, transverse space of piers not merely provide enough support but also ensure lateral stability of the bridge, as well as offering aside the maximum lateral clearance of the existing road. Meanwhile, the calculation results have important engineering practical values. which can provide basic data for the design, construction and maintenance of similar Bridges.
\end{abstract}

\section{Introduction}

Box-shaped cross-section has good structural properties and greater torsional stiffness, and be widely used in large-scale bridge structures [1]. Steel bridge with box section is especially satisfied with structure and construction requirements. Steel box girder has merits of high intensity, large bending torsional stiffness, good overall performance, light weight, high degree of factory operation, quick construction progress, and structures with box girders in the process of construction and service all have a good stability. Hence, this girder is used in large, long span bridges [2]. Steel girder with a long cantilever belt can reduce the self-weight of the bridges, the piers structural dimensions and bridge cost. However, steel box girder cantilever panels and stiffeners due to long-term exposure to the atmosphere, prone to steel box wall corrosion. In addition, closed of the steel box girder can improve the corrosion resistance of the steel structure. Therefore, a curved thin steel plate is added on the outside of the cantilever plate, and the stiffening rib of the cantilever plate is completely closed, which can avoid the corrosion problems caused by the stiffening rib of the steel box girder, especially the streamline shape design, which has superior wind resistant performance and concise appearance, smoothness and beauty. Ouyang Yongjin and Liu Shizhong et al [3-7] did a lot of works on the shear lag effect of steel box girder. The author and Chen Huifa did a lot of works on the dynamic response of continuous box 
girder under earthquake load [8-11], and obtained more accurate calculation results. After reviewing a large amount of data, the author found that there is little data on the research of natural vibration characteristics of large-span-to-span bridges. However, the research on the vibration problem of continuous steel box girder with large span and span ratio to obtain the maximum space under the existing municipal roads has very few reference values. In this paper, a three-dimensional finite element model of plate and shell considering the pilesoil interaction is established for a large-span, single-span, multi-compartment continuous steel box girder in Xiamen city. The vibration characteristics of the structure are analyzed. Incentive test comparative analysis of the test results. At the same time, the calculation results can also provide basic data for the design, construction and maintenance of the bridge and similar bridges, which has important engineering practical value.

\section{Project overview}

The length of a rapid trunk road in Xiamen City is 1080 meters, of which the length of steel box girder is 252 meters. The span of continuous steel box girder of equal height is arranged in two forms of $(40+55+40)$ meters and $(35+45+35)$ meters, where the design load is city A level and the clearance height is more than 5.0 meters. The continuous steel box girder adopts the single box multi-chamber section and the streamline shape design. The full width of the steel box girder top is 25.0 meters, the floor width is 13.5 meters, the length of the cantilever on both sides are 5.75 meters, the height of the steel box girder is 2.0 meters, Side of the welded steel beam, the lower flange design streamlined.

Bridge deck structure using orthotropic board, roof section thickness are $14 \mathrm{~mm}$, in order to adapt to the smooth curve of the plane curve, longitudinal rib section are used inverted T-type welding, transverse ribs general spacing $2.0 \mathrm{~m}$, diaphragm thickness $12 \mathrm{~mm}$ $\sim 36 \mathrm{~mm}$, floor thickness of $14 \mathrm{~mm} \sim 36 \mathrm{~mm}$, the general board thickness $14 \mathrm{~mm} \sim 20 \mathrm{~mm}$. Bridge pier is slightly open at the top of the double-rectangular portal pier, near the road with semi-elliptical softening. The rectangular column of bridge pier is $2 \times 1.6 \mathrm{~m}$ with a thickness of $1.6 \mathrm{~m}$ on the side. The pier top of the connecting pier is locally thickened to meet the need of arranging two supports, and the pier in the pier spacing of the pier adopts $6.5 \mathrm{~m}$. Abutment reinforced concrete U-abutment. The basis of pile foundation, pile diameter $\Phi 1.6 \mathrm{~m}$. In this paper, a large span ratio of 0.45 three-span continuous steel box girder $(40+55+40) \mathrm{m}$ as the research object, its natural vibration characteristics of a special study. Continuous steel box girder bridge cross section shown in Figure 1.

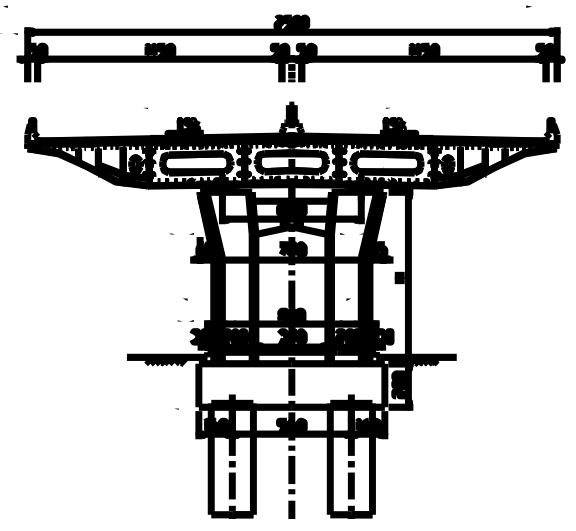

Figure. 1 Cross-section of Steel Box Girder (Unit:cm) 


\section{Finite element model}

The vibration characteristics of the structure are mainly determined by the stiffness and quality of the structure, thus accurately simulating the stiffness and mass of the structural members [13-14]. A three-dimensional finite element model of continuous steel box girder was established with the help of the large-scale finite element structural analysis software ANSYS. The shell63 elemnt was used to simulate the pier and steel box girder. In the simulation process, in order to avoid or reduce the appearance of morbid units as much as possible, a custom meshing unit is adopted, which can faithfully reflect the change of structure shape and detail.

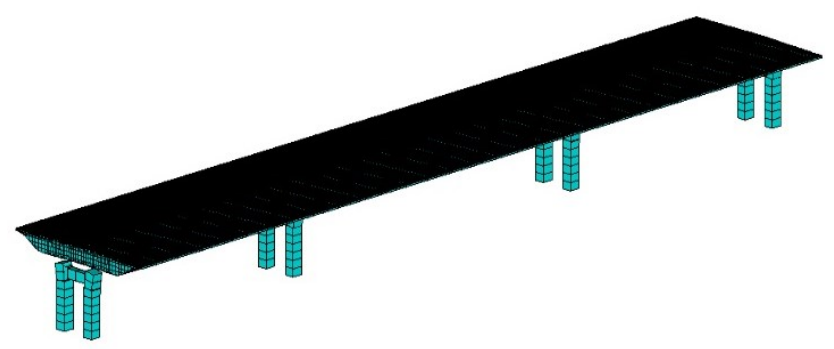

Figure. 2 Finit Elemet Model of the Continuous Steel Box Girder-bridge

The three-span continuous steel box girder adopts the isolation rubber bearing, with four unidirectional movable supports, three bidirectional movable supports and a fixed support. The support and the box girder bottom plate are connected by the support plate. In the finite element model, the support type is constrained and simulated according to the corresponding line displacement. For the steel box girder, the rigidity of the shell element is the rigidity of the box girder itself, and the quality is the quality of the steel box girder. The deck pavement, railings, sidewalks, lamp posts, etc. are all calculated in the form of linear density. According to the consolidation simulation, the bridge piers and cap are included in the joint action of pile-soil-structure. The bridge deck pavement is calculated according to the additional mass unit, and its dynamic characteristics are analyzed in the spatial analysis model. The finite element model of continuous steel box girder is shown in Fig.2.

\section{Analysis of structural vibration characteristics}

\subsection{Structural calculation theory}

Solving the structure of the natural frequency (period) is essentially the problem of solving a generalized eigenvalue. There are many ways to solve the eigenvalue problem, such as inverse iteration method, Rayleigh-Leeds method, Ritz vector method, subspace iteration method, Lanczos vector method [15]. At present, the subspace iteration method is widely used, and it can be applied to solve some eigenvalue problems. It is the most commonly used and effective method for solving large matrix eigenvalue problems. In keeping the orthogonal condition, assuming that $\mathrm{n}$ initial vectors and repeating iterations until the number of iterations is big enough to satisfy the convergence condition, can get first $\mathrm{k}(\mathrm{k}<\mathrm{n})$ of the matrix eigenvalue and characteristic vector. Therefore, in this paper, the method of subspace iteration is used to calculate the self - vibration characteristics of large - width span - span steel box girder. 
Vibration mode and frequency of structural free vibration are important dynamical characteristic parameters of structural system, which play an important role in solving the dynamic response of structural system [16].

The finite element free vibration equation of the structural system is:

$$
[K]\{x\}=\omega^{2}[M]\{x\}
$$

In the formula: $[K]$ is total stiffness matrix; $[M]$ means total mass matrix; $\{x\}$ for the mode vector; $\omega_{\text {Is the circular frequency. }}$

From formula (1), we can get the Rayleigh quotient:

$$
\omega^{2}=\frac{\{x\}^{T}[K]\{x\}}{\{x\}^{T}[M]\{x\}}
$$

Pulsating method is also called the environment random excitation method. The structure under the action of environmental incentive, such as disturbances caused by ground pulsation, natural wind, vehicle, machine etc. Although the amplitude of structure is minuscule, but the frequency of the pulse response contains quite rich. Without any excitation equipment, it can apply to the whole structural natural vibration characteristics of the test. The ambient vibration response of large and wide span of continuous steel box girders was picked up by ultra-low frequency acceleration sensor. For accurate steel box girder vibration response, In this paper, the environmental vibration data of each measuring point is filtered to high and low frequency signal components. Then the data were analyzed by power spectrum analysis and mutual power spectrum, In the end, we can obtain the coherence function and phase difference function of the signal power spectral density function of each measurement point and the reference point signal, the power spectral density and coherence function determine the frequency of each mode, and the power spectral density and phase difference function determine the modes of each mode.

\subsection{Comparison of dynamic analysis and measured results}

\subsubsection{Analysis of self-vibration characteristics}

In structural dynamic characteristics, the self-oscillation frequency reflects the stiffness of the structure to a large extent, and the first few steps have the control effect on the dynamic characteristics. Therefore, in the analysis of the dynamic characteristics of the bridge, it is necessary to accurately calculate self-vibration frequency and corresponding vibration mode of the bridge, and analyze the mode characteristics. In order to calculate the necessary self-vibration frequency and the corresponding mode of vibration, the bridge adopts sub-space iterative method to calculate the bridge mode. Due to the limited space, this paper only lists the results and modes of the first 10 self-vibration characteristics, as shown in table 1 and FIG. 3 respectively.

Based on the above calculation model, the necessary self-oscillation frequency and corresponding mode vector are determined by subspace iterative method. The first 10 vibration characteristics and frequency are listed in table 1. 
Table. 1 Comparison of Natural Frequency and Vibration Type in First 10 Steps

\begin{tabular}{|c|c|c|c|c|c|}
\hline Order & Feature & $\begin{array}{c}\text { Frequenc } \\
(\mathrm{Hz})\end{array}$ & Order & Feature & Frequency $(\mathrm{Hz})$ \\
\hline 1 & $\begin{array}{l}\text { Pier2 vertical } \\
\text { bending }+ \\
\text { Longitudinal } \\
\text { vibration of the } \\
\text { beam }\end{array}$ & 1.817 & 6 & $\begin{array}{l}\text { Beam first-order } \\
\text { anti-symmetry } \\
\text { twist }\end{array}$ & 3.316 \\
\hline 2 & $\begin{array}{c}\text { Longitudinal } \\
\text { vibration of pier2 }+ \\
\text { Beam vertical } \\
\text { bending }\end{array}$ & 2.025 & 7 & $\begin{array}{l}\text { Beam first-order } \\
\text { symmetry twist }\end{array}$ & 3.514 \\
\hline 3 & $\begin{array}{c}\text { First-order } \\
\text { symmetrical beam } \\
\text { torsion }\end{array}$ & 2.52 & 8 & $\begin{array}{l}\text { Beam second- } \\
\text { order symmetry } \\
\text { twist }\end{array}$ & 4.109 \\
\hline 4 & $\begin{array}{l}\text { Second-order } \\
\text { beam anti- } \\
\text { symmetrical } \\
\text { vertical bending }\end{array}$ & 3.072 & 9 & $\begin{array}{c}\text { Pier } \\
\text { longitudinal } \\
\text { vibration }+ \text { anti- } \\
\text { symmetrical beam } \\
\text { torsion }\end{array}$ & 4.590 \\
\hline 5 & $\begin{array}{c}\text { Second-order } \\
\text { beam symmetrical } \\
\text { vertical bending }\end{array}$ & 3.309 & 10 & $\begin{array}{c}\text { Main span first } \\
\text { antisymmetric } \\
\text { vertical bending }+ \\
\text { torsion }\end{array}$ & 5.655 \\
\hline
\end{tabular}

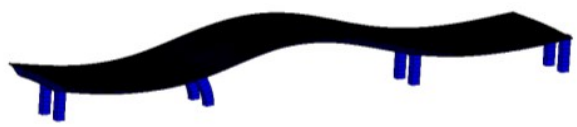

The 1st order vibration mode

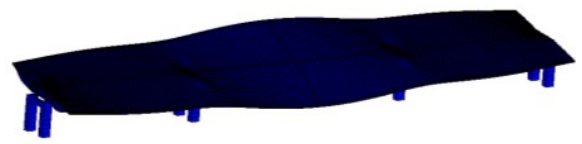

The 3rd order vibration mode

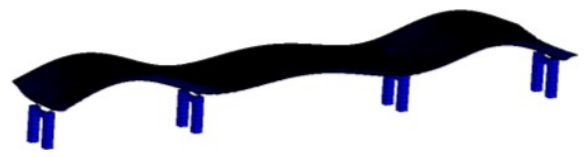

The 5 th order vibration mode

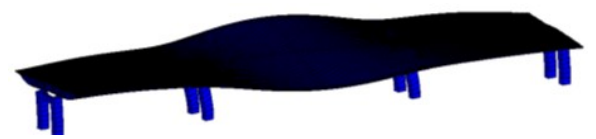

The 7 th order vibration mode

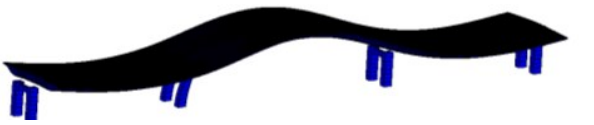

The 2nd order vibration mode

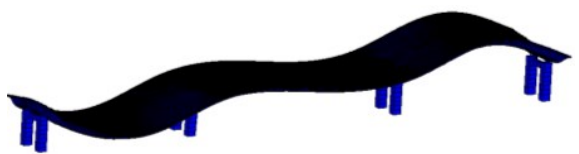

The 4 th order vibration mode

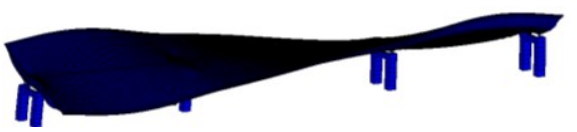

The 6 th order vibration mode

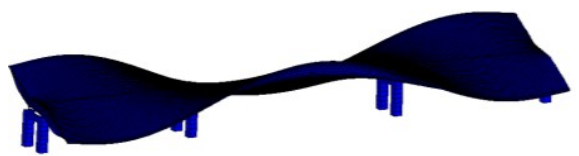

The 8 th order vibration mode 


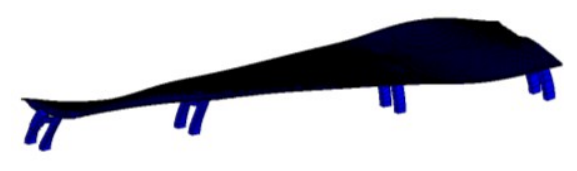

The 9th order vibration mode

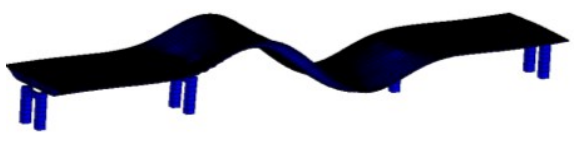

The 10th order vibration mode

Figure. 3 Structure Mode of Vibration in First 10 Steps

As can be seen from figure 3, the self-vibration characteristics of the bridge show the following characteristics:

The bridge pier belongs to the low-fat structure, and only one fixed support (2 \# pier top) is set in the three-span continuous bridge, and the longitudinal stiffness of the bridge is weaker than the horizontal and vertical direction of the bridge. Therefore, the first mode of the bridge shows that the whole bridge has the vertical vibration of the whole bridge and the bending vibration of the bridge pier, with the characteristics of two and a half wave vertical vibrations of the main $\operatorname{span}(\mathrm{L}=55 \mathrm{~m})$.

The second order vibration shows the vertical half-wave vibration of the main span, the vibration frequency of $2.025 \mathrm{~Hz}$ is $11.43 \%$ higher than the first order frequency of the longitudinal vibration of the bridge.

The third order vibration mode is given priority to span structure first-order symmetric torsional vibration, the vibration frequency of $2.52 \mathrm{~Hz}$, in spite of bridge deck width is 25.0 $\mathrm{m}$, but the bridge lateral support spacing is only $6.5 \mathrm{~m}$, its vibration frequency is $38.6 \%$ higher than the vertical bending. It is shown that the bridge lateral support $6.5 \mathrm{~m}$ in maximum limit to ensure lateral stability of the bridge to set aside the maximum lateral clearance at the same time.

The 4th and 5th order vibration frequency were $3.072 \mathrm{~Hz}$ and $3.309 \mathrm{~Hz}$, vertical symmetric and antisymmetric vibration modes respectively, showed a double root vibration characteristics, respectively for the two sides across the vertical half wave bending vibration, on both sides of the bridge structure in the cross is symmetrical layout, the characteristics of vibration frequency and the corresponding appear heavy root. It is shown that the finite element model of the bridge is correct and reflects the dynamic characteristics of the bridge.

The 6th order for antisymmetric vibration torsional vibration, but also reflect the characteristics of this bridge transverse bearing set only $6.5 \mathrm{~m}$, the vibration frequency of $3.316 \mathrm{~Hz}$ and on both sides of the bridge across the vertical vibration frequency of $3.072 \mathrm{~Hz}$ and $3.309 \mathrm{~Hz}$ close to that bridge transverse span width of $6.5 \mathrm{~m}$ is a better support.

Span structures of the 7 th order vibration mode is given priority to the first order torsional vibration, the vibration frequency of $3.514 \mathrm{~Hz}$, even though the deck width is 25.0 $\mathrm{m}$, and the lateral support of bridge middle span of only $6.5 \mathrm{~m}$. It is suggestted that bridge lateral support $6.5 \mathrm{~m}$ can maximally ensure lateral stability while left transverse bridge to the world's largest net.

The 8th order vibration is the high order of the whole bridge, which is called torsional vibration, and the vibration frequency is $4.109 \mathrm{~Hz}$.

The 9th vibration is the span of the bridge and the longitudinal vibration frequency of the $2 \#$ piers is $4.59 \mathrm{~Hz}$ respectively. The vibration characteristics of transverse symmetry of bridge structure are reflected.

The 10th order vibration is the high order resistance of the bridge. The vibration frequency is $5.655 \mathrm{~Hz}$. The frequency of vibration is $23.2 \%$ higher than that of the ninth stage, and there is a jump in frequency.

From the bridge the first ten order vibration frequency and vibration model, bridge longitudinal, vertical and torsional vibration frequency is smaller, vertical and torsional vibration of beam body appear alternately, showed that the height of the steel box girder 
structure, the density of diaphragm plate set reasonable, pier transverse spacing Settings to ensure the premise of bridge piers can provide enough support ability and can ensure the lateral stability of the continuous steel box girder, and also to allow maximum lateral clearance of the existing road.

In the first ten steps, there is no single horizontal vibration of the bridge, indicating that the transverse stiffness of the bridge is far greater than that of vertical and torsional rigidity.

\subsubsection{Comparison between the calculated results and the measured results}

The finite element program ANSYS is used to analyze the dynamic characteristics of steel box girder with large width to span ratio. The results of natural vibration of bridge structure are compared with the results of ambient excitation test. For limited space only the first 10 order comparison results and mode shapes are given, as shown in table 2.

From table 2, it is shown that the first vibration mode of the bridge is the vertical vibration of the 2 pier and the longitudinal vibration of the beam. The measured frequency is $1.99 \mathrm{~Hz}$, and the theoretical self - vibration frequency is $1.817 \mathrm{~Hz}$. The second order mode is the longitudinal vibration of the 2 pier and the vertical bending of the beam. The measured frequency is $2.79 \mathrm{~Hz}$, and the theoretical self - vibration frequency is $2.025 \mathrm{~Hz}$. The third order mode is the first symmetric torsion of the beam. The measured frequency is $2.93 \mathrm{~Hz}$, and the theoretical self - vibration frequency is $2.520 \mathrm{~Hz}$. The fourth order mode of vibration is the two order anti-symmetric vertical bending of the beam. The measured frequency is $3.12 \mathrm{~Hz}$, and the theoretical self - vibration frequency is $3.072 \mathrm{~Hz}$. The fifth order mode is the second order symmetrical vertical bending of the beam. The measured frequency is $3.71 \mathrm{~Hz}$, and the theoretical self - vibration frequency is $3.309 \mathrm{~Hz}$. The calculation results show that the measured frequency of self-vibration is greater than the theoretical calculation. The minimum value of the measured damping ratio is $2.32 \%$ and the maximum value is $6.86 \%$. 
Table. 2 Comparison of Natural Frequency and the Environmental Stimulation

\begin{tabular}{|c|c|c|c|c|}
\hline Order & $\begin{array}{c}\text { Measured } \\
\text { self-vibration } \\
\text { frequency } \\
(\mathrm{Hz})\end{array}$ & $\begin{array}{c}\text { Damping } \\
\text { Ratio } \\
(\%)\end{array}$ & $\begin{array}{c}\text { Theoretical } \\
\text { self-vibration } \\
\text { frequency } \\
(\mathrm{Hz})\end{array}$ & Vibration mode \\
\hline 1 & 1.99 & 5.55 & 1.817 & $\begin{array}{c}\text { Pier2 vertical bending }+ \\
\text { Longitudinal vibration of the } \\
\text { beam }\end{array}$ \\
\hline 2 & 2.79 & 2.32 & 2.025 & $\begin{array}{c}\text { Longitudinal vibration of } \\
\text { pier2 + Beam vertical bending }\end{array}$ \\
\hline 3 & 2.93 & 6.86 & 2.520 & $\begin{array}{c}\text { First-order symmetrical } \\
\text { beam torsion }\end{array}$ \\
\hline 4 & 3.12 & 3.49 & 3.072 & $\begin{array}{c}\text { Second-order beam anti- } \\
\text { symmetrical vertical bending }\end{array}$ \\
\hline 5 & 3.71 & 6.00 & 3.309 & $\begin{array}{c}\text { Second-order beam } \\
\text { symmetrical vertical bending }\end{array}$ \\
\hline 6 & l & l & 3.316 & $\begin{array}{l}\text { Beam first-order anti- } \\
\text { symmetry twist }\end{array}$ \\
\hline 7 & / & / & 3.514 & $\begin{array}{l}\text { Beam first-order symmetry } \\
\text { twist }\end{array}$ \\
\hline 8 & 4.49 & 4.27 & 4.109 & $\begin{array}{l}\text { Beam second-order } \\
\text { symmetry twist }\end{array}$ \\
\hline 9 & / & / & 4.591 & $\begin{array}{l}\text { Pier longitudinal vibration }+ \\
\text { anti-symmetrical beam torsion }\end{array}$ \\
\hline 10 & l & l & 5.655 & $\begin{array}{l}\text { Main span first } \\
\text { antisymmetric vertical bending } \\
+ \text { torsion }\end{array}$ \\
\hline
\end{tabular}

The measured vertical bending fundamental frequency of steel box girder is $2.79 \mathrm{~Hz}$, the theoretical fundamental frequency is $2.025 \mathrm{~Hz}$. The measured fundamental frequency of symmetrical torsion is $2.93 \mathrm{~Hz}$ and the theoretical fundamental frequency is $2.520 \mathrm{~Hz}$. The theoretical calculated value and the measured natural vibration characteristic of the steel box girder are similar. The measured frequency is greater than the theoretical value. It indicated that the actual stiffness of the joint is greater than the theoretical stiffness and the quality of the bridge is good. In addition, it shows that the dynamic calculation model of the bridge is reasonable and the calculation method is correct. The measured the first eight order main damping ratio is $2.32 \% \sim 6.86 \%$, which is close to the general bridge damping ratio of $0.01 \sim 0.10$, belonging to the normal range. It shows that the bridge has good dynamic performance.

\section{Conclusion}

(1) In the design of steel box girder-bridge, a curved thin steel plate is built on the outside of the cantilever plate to avoid the corrosion of the steel box girder cantilevered ribs. The shape design of streamline shape is designed, the bridge type is beautiful, it is more advantageous to enhance the bridge structure's anti-wind ability.

(2) Through discrete analysis and accurate simulation of steel box girder-bridge, ANSYS software is used to analyze the structure and use the environmental excitation to test the bridge. 
(3) The results show that, from the first ten stages of the bridge vibration frequency and vibration mode, the bridge longitudinal, vertical and torsional vibration frequency difference is small. The vertical and torsional vibrations of the girder alternately appear, which shows that the height of the steel box girder structure and the density of the diaphragm are reasonable and feasible. The lateral spacing of bridge piers can ensure the lateral stability of continuous steel box girders and provide the maximum horizontal clearance to the existing roads under the premise of ensuring sufficient pier supporting capacity.

(4) The calculation results of the bridge can also provide basic data for the design, construction and maintenance of similar bridges. It is of great practical value for engineering.

\section{References}

1. Guo Jin-qiong, Fang Zhen-zheng, Zheng Zhen. Design Theory of Box girder [M]. Beijing : China Communications Press, 2008

2. Xiang Hai-fan. Advanced Theory of Bridge Structures [M].Beijing: China Communications Press, 2008

3. Liu Shi-zhong. Non-uniform thin wall box analysis of considering both shear lag and shear deformation [J].China Journal of Highway and Transport, 2002,15 (3);61-63.

4. OUYANG Yong-jin. Investigation of Shear Lag Effect of Continuous Steel Box Girder Bridge with Great Width-to-Span Ratio [J].World Bridges, 2009, 14 0(1); 29-32.

5. Zhang Yuan-hai, Wang Lai-lin, Li Qiao. One-dimensional finite element method and its application for the analysis of shear lag effect in box girders [J]. CH INA CIVIL ENG INEERING JOURNAL, 2010, 40(80):44-50

6. ZHOU Sh-i jun, YANG Z-i jiang. Finite Beam Element for Analysis of Effect of Concentrated Bending Moments on Shear Lag in Box Girders [J]. JOURNAL OF THE CHINA RAILWAY SOCIETY, 2010, 32(03):90-94

7. ZHOU Mao-ding, LI Li-yuan, ZHANG Yuan-hai. Research on Shear-lag Warping Displacement Function of Thin-walled Box Girders [J]. China Journal of Highway and Transport, 2015, 28(6): 67-73.

8.Yin Haijun, Xu Lei, Shen Yuekui, Lin Qingning, Yan Wen Study of Seismic damages of Bridges in Wenchuan Earthquake[J].J.Xi'an Univ. of Arch. \& Tech.(Natural Science Edition),2008,40(5):672-677.

9. YIN Hai-jun. Static and dynamical analysis of Fu rong-jiang Extra-Long Bridge [D]. Gansu: Lanzhou Jiao tong University, 2007.

10. YIN Hai-jun,LI Zi-qing, GUO Qi, YAN Wen, HAN Fei. Study on the dynamic characteristics of long span continuous rigid frame bridge with high wall piers [J].J. Xi'an Univ. of Arch. \& Tech. (Natural Science Edition), 2010, 42(5):663-668.

11 .Chen Huifa (U.S) Duan Lian (U.S), Translated by Cai Zhongmin and Wu Jun. Aseismatic Design of Bridges [M]. Beijing: China Machine Press, 2008

12 .LIU Yan-hui, TAN Ping, ZHOU Fu-lin, WENLIUHAN Heisha, MERCAN O. Shaking Table Test for Seismic Simulation of Continuous Isolation Girder Bridge with High Piers[J]. China Journal of Highway and Transport, 2015, 28(2): 60-68, 94.

13. Zhang Li-ming. Application method and example of algor and ansys on bridge engineering [M]. Beijing: People Communication Publishing House, 2003

14. Fan Li-chu,Hu Shi-de, Ye Ai-jun . Seismic design of long-span bridges [M]. Beijing:People Communication Publishing House, 2001.

15.Wu Hong-qing, Ren Xia. Structural finite element analysis [M]. Beijing:China railway publishing house, 2000 . 
16 .Zhu Ledong. Modal Identification of Bridges [J]. JOURNAL OF TONGJI UNIVERSITY, 1999, 27(2):179-183. 